\title{
Efeitos de rizobactérias na promoção de crescimento e controle de fitopatógenos em sementes de paricá
}

O paricá (Schizolobium amazonicum Huber ex Ducke) é considerado uma espécie de grande potencial para produção madeireira, pelo seu rápido crescimento, excelente adaptabilidade pela qualidade da madeira. Porém, pouco se conhece a respeito do seu desenvolvimento utilizando rizobactérias na fase de mudas oriundas de sementes. Diante disso, objetivo deste trabalho foi avaliar o controle de patógenos em sementes de paricá e a promoção de crescimento induzidas por rizobactérias. Deste modo, utilizou-se dois isolados de rizobactérias promotoras do crescimento de plantas, Pseudômonas sp. e Burkholderia sp.. O experimento foi conduzido no Laboratório de Microbiologia e Saúde e em casa de vegetação da Universidade Estadual da Região Tocantina do Maranhão. O delineamento experimental utilizado foi inteiramente casualizado, com quatro tratamentos e cinco repetições. Os tratamentos testados foram sementes não microbiolizada (T1); sementes microbiolizadas com Pseudômonas sp. (T2); sementes microbiolizadas com Burkholderia sp. (T3); sementes microbiolizadas com Pseudômonas sementes não microbiolizada (T1); sementes microbiolizadas com Pseudômonas sp. (T2); sementes microbiolizadas com Burkholderia sp. (T3); sementes microbiolizadas com Pseudômonas
sp. e Burkholderia sp. (T4). Para o teste de sanidade de sementes foram usadas 400 sementes para análise de fitopatógenos, enquanto que para o teste in vitro foram usadas 200 sementes sp. e Burkholderia sp. (T4). Para o teste de sanidade de sementes foram usadas 400 sementes para análise de fitopatógenos, enquanto que para o teste in vitro foram usadas 200 sementes
submetidas a microbiolização com as rizobactérias. Em casa de vegetação foram utilizadas 200 sementes, e as amostras foram analisadas quanto a germinação com 10,20 e 30 dias, altura de plantas, comprimento radicular, diâmetro basal, biomassa fresca da parte aérea e da raiz e biomassa seca da parte aérea e da raiz com 30 dias. Foram identificadas as espécies fúngicas: Penicillium sp., Aspergillus flavus, A. glaucus, A. niger, e Trichoderma sp. O tratamento T4 apresentou eficiência na redução total da incidência fúngica nas sementes de paricá. Foram constatadas correlações positivas entre o parâmetro controle de fitopatógenos em sementes de paricá e uso de rizobactérias, conquanto em casa de vegetação a inoculação de rizobactérias não promoveu significativamente o crescimento das plântulas.

Palavras-chave: Schizolobium amazonicum; Espécies amazônicas; Espécies nativas; Silvicultura.

\section{Effects of rizobacteria on the promotion of growth and control of phytopatogens in paricá seeds}

\begin{abstract}
Lettuce is considered the most important leafy vegetable in Brazil. The production in a greenhouse or protected environment, using substrate, also called cultivation without soil, has been Lettuce is considered the most important leafy vegetable in Brazil. The production in a greenhouse or protected environment, using substrate, also called cultivation without soil, has been
gaining prominence in the world scenario, due to the need for soil conservation. Thus, the search for alternative materials to compose substrates is necessary and relevant, taking into account gaining prominence in the world scenario, due to the need for soil conservation. Thus, the search for alternative materials to compose substrates is necessary and relevant, taking into account
the agro-industrial aptitude of each region in order to allow the use of waste that is abundantly available and the reduction of production costs. The objective of evaluating industrial residues used as substrates, and their effects on the development and production of lettuce grown in a protected environment. This experiment was developed at the Federal Rural University of the Amazon, campus of Paragominas, in the experimental area of Horticulture. A completely randomized design was used with four treatments (rice straw, soy residue, mixture $=$ rice straw ( $35 \%$ ) + soy residue (35\%) + black sand (30\%) and black sand as a control). The following characteristics were evaluated: number of leaves, Weight (kg), Root weight $(\mathrm{g})$, cycle, stem length (cm), economic productivity ( $\mathrm{kg}$ ), leaf area (RA) ( $\mathrm{cm} 2$ ), leaf area index (IAF), Leaf Area Ratio (RAF) ( $\mathrm{cm} 2 \mathrm{~g}-1)$, specific leaf area (AFE) ( $\mathrm{cm} 2 \mathrm{~g}-1)$, leaf weight ratio (RPF), amount of water in the aerial part (QAPA), weight leaf specific (PEF) $(\mathrm{g} \mathrm{cm} 2)$. All data obtained were analyzed statistically through analysis of variance, with the $F$ test. The Tukey test (5\%) was used to compare means. The best substrate for lettuce production, without soil, in a greenhouse, is the soy residue, because in this substrate the cultivar veneranda showed the highest productivity and the best morphophysiological indexes, demonstrating the possibility of using this industrial residue as an alternative substrate.
\end{abstract}

Keywords: Schizolobium amazonicum; Amazonian species; Native species; Forestry.

Topic: Desenvolvimento, Sustentabilidade e Meio Ambiente

Reviewed anonymously in the process of blind peer.

Leanne Teles Pereira (iD

Universidade Estadual da Região Tocantina do Maranhão, Brasil http://lattes.cnpq.br/6857374184743865

http://orcid.org/0000-0002-8230-3472

leanne.teles@hotmail.com

Kele Sousa Pires Andrade (iD

Universidade Estadual da Região Tocantina do Maranhão, Brasil http://lattes.cnpq.br/7515596782122130

http://orcid.org/0000-0001-7083-3962

kelesousapires@gmail.com

Sheila Elke Araújo Nunes (iD

Universidade Estadual da Região Tocantina do Maranhão, Brasil http://lattes.cnpq.br/2570242039075491

http://orcid.org/0000-0002-2309-7314

sheilanunes@uemasul.edu.br
Received: 10/08/2020

Approved: 21/09/2020

\author{
Márcia Guelma Santos Belfort (iD) \\ Unidade Ensino do Sul do Maranhão, Brasil \\ http://lattes.cnpq.br/1748392086009047 \\ http://orcid.org/0000-0003-3131-2237 \\ marciguelma@hotmail.com \\ Fabiana dos Santos Oliveira (iD \\ Universidade Estadual da Região Tocantina do Maranhão, Brasil \\ http://lattes.cnpq.br/9870857613984821 \\ http://orcid.org/0000-0001-8346-0886 \\ fs_Oliveira19@yahoo.com.br \\ Ivaneide de Oliveira Nascimento (iD) \\ Universidade Estadual da Região Tocantina do Maranhão, Brasil \\ http://lattes.cnpq.br/5127803057876571 \\ http://orcid.org/0000-0001-7095-7092 \\ ivaneide@uemasul.edu.br
}

Referencing this:

PEREIRA, L. T.; ANDRADE, K. S. P.; NUNES, S. E. A.; BELFORT, M. G. S.; OLIVEIRA, F. S.; NASCIMENTO, I. O.. Efeitos de rizobactérias na promoção de crescimento e controle de fitopatógenos em sementes de paricá. Revista Ibero Americana de Ciências Ambientais, v.11, n.5, p.539-548, 2020. DOI: http://doi.org/10.6008/CBPC2179$\underline{6858.2020 .005 .0049}$ 


\section{INTRODUÇÃO}

O cultivo de espécies florestais nativas é uma alternativa economicamente viável e de menor impacto ambiental frente às culturas exóticas, como o eucalipto e o dendenzeiro (MARQUES et al., 2006; OLIVEIRA et al., 2012). Reduzindo a pressão do desmatamento sobre áreas de mata nativa, sobretudo nas regiões Norte e Nordeste do Brasil (IWAKIRI et al., 2010; OLIVEIRA et al., 2012).

Uma espécie que tem mostrado com potencial na Região Amazônica é o Paricá (Schizolobium amazonicum Huber ex Ducke) (MARQUES et al., 2006; IWAKIRI et al. 2010). Apresentando características de espécies heliófilas, mostrando a adaptação da espécie a ambientes com alta incidência de radiação solar. É uma árvore decídua, de rápido crescimento, que atinge até $40 \mathrm{~m}$ de altura e $100 \mathrm{~cm}$ de DAP (diâmetro à altura do peito) na idade adulta (CARVALHO, 2007; AMATA, 2009). Devido ao seu rápido crescimento e potencial silvicultural, o paricá vem cada vez mais sendo usados para reflorestamento (MARQUES et al., 2006), sendo indicada para utilização em áreas a partir de $200 \mathrm{~m}^{2}$ (GOMES et al., 2019) e também para cultivo em regime de integração Lavoura Pecuária - Floresta (iLPF) sem prejudicar o seu crescimento e produtividade (SILVA et al., 2018). A sua madeira apresenta coloração branca e tem densidade média de $0,40 \mathrm{~g} / \mathrm{cm}^{3}$; a sua produtividade média anual está na faixa de 25 a $30 \mathrm{~m}^{3} / \mathrm{ha} / \mathrm{ano}$, semelhante ao crescimento das espécies de Pinus e superior ao da Teca (IWAKIRI et al., 2010). O ciclo de corte de sete anos é praticado para lâminas aplicadas em compensados (AMATA, 2009). A espécie apresenta características tecnicamente viáveis para produção de painéis, como os aglomerados e laminados (MARQUES et al., 2006; IWAKIRI et al., 2010).

Devido às sementes constituírem a principal via de propagação do paricá, o controle da qualidade sanitária e fisiológica da semente é de grande importância para o sucesso da produção (SOUZA et al., 2003). Em virtude da ampla quantidade de fitopatógenos que podem estar associados às sementes, estas podem introduzir patógenos, gerando efeitos negativos, como a redução da qualidade fisiológica (vigor e germinação), bem como disseminar patógenos para áreas isentas de doenças. Desta forma, tem-se buscado alternativas de controle de doenças que sejam menos prejudiciais ao meio ambiente e ao homem, visando à redução ou eliminação do uso de defensivos (RUFINO et al., 2018).

Ademais, o conhecimento sobre a potencialidade do desenvolvimento de tecnologias específicas para ativação de mecanismos de defesa de plantas é uma técnica alternativa sustentável, frente ao uso indiscriminado de defensivos (VIEIRA JÚNIOR et al., 2013). Nesse sentido, tem-se buscado por um controle alternativo de fitopatógenos com o uso de técnicas menos danosas ao meio ambiente, onde o emprego de rizobactérias é uma estratégia promissora (ROMEIRO, 2007; RUFINO et al., 2018).

As rizobactérias são de vida livre, simbióticas ou endofíticas, possuem várias habilidades que as caracterizam como benéficas para as culturas ou plantas como um todo. Produzem substâncias inibitórias, como antibióticos, ácidos orgânicos, sideróforos, antifúngicos e bacteriocinas (CESA-LUNA et al., 2020; MOIN et al., 2020; WANG et al., 2020).

Uma das formas de uso de rizobactérias é para a promoção do crescimento de plantas (RPCP), são capazes de fixar nitrogênio, mineralizar fosfatos, competir por ferro e indução de resistência de plantas 
(ROMEIRO, 2005). Estimulando o crescimento e produtividade sob condições de estresse salino (PHOUR et al., 2020); minimizam os efeitos na planta sob estresse de metais pesados e aumenta a biomassa da planta em 100\% (SHILEV et al., 2019), além disso são capazes de degradar pesticidas (RODRÍGUEZ et al., 2020).

A utilização de rizobactérias para a promoção do crescimento de plantas direta ou indiretamente, possui a vantagem de diminuir a utilização de insumos químicos, com benefícios tanto de ordem econômica quanto de ordem ecológica, uma vez que tais produtos podem contaminar o meio ambiente (ROMEIRO, 2007; FREITAS, 2007; RODRÍGUEZ et al., 2020). Os gêneros bacterianos Pseudômonas e Burkholderia estão entre os que mais se destacam como promotores de crescimento e produtores de substâncias inibidoras de fitopatógenos (NASCENTE et al., 2016; SHILEV et al., 2019; CESA-LUNA et al., 2020; RODRÍGUEZ et al., 2020; MOIN et al., 2020; WANG et al., 2020; PHOUR et al., 2020).

Diante do exposto, a utilização de rizobactérias como agentes de controle biológico de fitopatógenos e como promotoras de crescimento têm se mostrado como excelente alternativa para melhorar o desenvolvimento de plantas. E apesar da importância do Paricá (Schizolobium amazonicum Huber exDucke), poucos estudos avaliam o potencial de rizobactérias na germinação, sanidade das sementes e no crescimento de mudas de espécies nativas lenhosas (SIVIERO et al., 2008; OLIVEIRA et al., 2012; CELY et al., 2016). Logo, objetivou-se avaliar o controle de patógenos em sementes de paricá e a promoção de crescimento induzidas por rizobactérias.

\section{METODOLOGIA}

O experimento foi conduzido no Laboratório de Microbiologia e Saúde e em Casa de Vegetação da Universidade Estadual da Região Tocantina do Maranhão - UEMASUL/ Campus Imperatriz (5³2'07"S $\left.47^{\circ} 28^{\prime} 59^{\prime \prime} \mathrm{W}\right)$, no período de setembro a dezembro de 2018. Foram utilizadas sementes de paricá (Schizolobium amazonicum Huber ex. Ducke) cedidas pela EMBRAPA. Utilizou-se dois isolados de rizobactérias promotoras do crescimento de plantas, Pseudômonas sp. e Burkholderia sp., cedidos pelo Laboratório de Proteção de Plantas da Universidade Federal Rural da Amazônia (UFRA).

Para a realização dos experimentos in vitro e em casa de vegetação, foi adotado o delineamento inteiramente casualizado, consistindo de quatro tratamentos com cinco repetições: T1 - Sementes não microbiolizada; T2 - Sementes microbiolizadas com Pseudômonas sp.; T3 - Sementes microbiolizadas com Burkholderia sp.; e T4- Sementes microbiolizadas com Pseudômonas sp. e Burkholderia sp.

\section{Teste de Sanidade de sementes}

Para o teste de sanidade de sementes aplicou-se o método do papel de filtro (Blotter Test) (BRASIL, 2009), com a utilização de 400 sementes. Inicialmente, as sementes de paricá foram desinfestadas, por meio de imersão em uma solução de hipoclorito de sódio ( $\mathrm{NaOCl}$ ), a 2\% por 3 minutos, seguida de tríplice lavagem com água destilada. Em seguida, todas as sementes foram colocadas em placas de petri, previamente esterilizadas, contendo três camadas de papel filtro, sendo distribuídas 10 sementes por placa. Posteriormente, as sementes foram incubadas em BOD com fotoperíodo à temperatura média de $26 \pm 5$ o $C$ 
durante sete dias. Após esse período, verificou-se a incidência fúngica nas sementes e a identificação dos mesmos, através das características morfológicas com auxílio de microscópio estereoscópico, lupa e com auxílio do livro Regras para análise de sementes (BRASIL, 2009). Além da identificação de fungos, foram avaliadas as percentagens de sementes sadias e germinadas.

\section{Preparo de suspensões das bactérias (testes in vitro)}

Para avaliar a redução da incidência dos fitopatógenos nas sementes de paricá, realizou-se o procedimento de microbiolização, o qual consiste em microbiolizar as sementes com os isolados das rizobactérias (Pseudômonas sp. e Burkholderia sp.), na forma de suspensão, de acordo com os tratamentos adotados para este estudo: T1 - Sementes não microbiolizada; T2 - Sementes microbiolizadas com Pseudômonas sp.;T3 - Sementes microbiolizadas com Burkholderia sp.;T4- Sementes microbiolizadas com Pseudômonas sp. e Burkholderia sp.

Desse modo, os isolados das rizobactérias (Pseudômonas sp. e Burkholderia sp.), foram multiplicadas em meio de cultura de Batata-Dextrose-Ágar (BDA), levadas à estufa bacteriológica para crescimento por 48 horas. Após o crescimento, realizou-se o preparo das suspensões. Adicionou-se água destilada e autoclavada a cada uma das placas contendo os isolados, sendo estas raspadas com o auxílio de uma lâmina de vidro esterilizada até a obtenção de suspensões dos isolados de rizobactérias, as quais foram ajustadas em espectrofotômetro para $\operatorname{OD} 540=0,5\left(10^{8} \mathrm{ufc} \cdot \mathrm{mL}^{-1}\right)$.

Após, as sementes foram imersas na suspensão de rizobactérias, de acordo com o tratamento, um total de 200 sementes, e agitadas durante 1 hora na mesa agitadora. Em seguida, as sementes foram distribuídas nas placas, usando-se para cada tratamento 50 sementes divididas em cinco repetições, sendo 10 sementes por placa de petri pelo método do papel de filtro em placas de Petri (BRASIL, 2009). As sementes de paricá microbiolizadas ficaram incubadas em BOD com fotoperíodo à temperatura média de $26 \pm 5$ oC durante sete dias. Após esse período, a avaliação de incidência fúngica dos patógenos foi realizada, examinando individualmente as sementes em microscópio para observação da incidência dos fitopatógenos.

\section{Experimento em casa de vegetação}

Para o experimento em casa de vegetação, 200 sementes foram microbiolizadas, em seguidas imersas na suspensão de rizobactérias, conforme o tratamento já mencionado. Após esse procedimento, as sementes permaneceram durante seis horas na mesa agitadora, antes da realização do plantio. Não foi realizada nenhuma técnica para quebra da dormência das sementes antes da semeadura. Para cada tratamento foram semeadas 50 sementes divididas em cinco repetições, em copos de plástico descartáveis, preenchidos com o substrato Bioplant, sendo uma semente por copo, com irrigação duas vezes ao dia.

No experimento em casa de vegetação foram avaliados e analisados parâmetros relacionados à germinação e ao crescimento: altura de planta, comprimento da raiz; diâmetro basal, massa da parte aérea e massa da raiz. Após a instalação do experimento, a contagem da germinação foi realizada em intervalos de 10, 20 e 30 dias. Considerando-se germinadas as sementes que originaram plântulas normais, com todas 
as estruturas essenciais, demonstrando assim, sua aptidão para produzirem plantas normais viáveis sob condições favoráveis de campo.

As plantas utilizadas para determinação de comprimento de parte aérea, radicular e diâmetro basal ao nível do solo, foram avaliadas 30 dias após o plantio, posteriormente foram realizadas a avaliação da biomassa fresca. A determinação do comprimento da parte aérea foi realizada por intermédio de uma régua graduada, sendo medido do colo ao maior ápice da ramificação $(\mathrm{cm}) .0$ comprimento radicular foi realizado utilizando-se uma régua graduada, sendo medido do colo à maior ponta da raiz $(\mathrm{cm})$. 0 diâmetro basal da planta foi realizado por meio de um paquímetro a uma altura de $0,04 \mathrm{~cm}$ acima do nível do solo.

Para a determinação da massa biomassa fresca procedeu-se com o acondicionamento das plantas em sacos de papel, previamente identificados por tratamento e repetição, levados à balança digital para pesagem (g). Em seguida, as plantas foram levadas para estufa de circulação forçada, com temperatura de $50^{\circ} \mathrm{C}\left( \pm 5^{\circ} \mathrm{C}\right)$ por 48 horas para obtenção da biomassa seca.

\section{Delineamento experimental}

O delineamento experimental adotado foi inteiramente casualizado, com quatro tratamentos de 50 sementes com cinco repetições. Utilizou-se o software computacional Sistema para Análise de Variância SISVAR (FERREIRA, 2000), inicialmente realizando a análise de variância, comparando-se as médias dos tratamentos pelo teste de Tukey $(P>0,05)$.

\section{RESULTADOS E DISCUSSÃO}

No teste de sanidade realizado, as sementes de paricá (Schizolobium amazonicum Huber ex. Ducke) apresentaram baixa taxa de germinação com apenas 2,25\%, tendo $22,75 \%$ de sementes infectadas e 77,25 de sementes sadias. Fernandes et al. (2019) identificou resultado semelhante ao nosso estudo, com um percentual de 3\% das sementes germinadas de paricá. Segundo Nunes et al. (2008), a germinação das sementes é determinada principalmente pela absorção de água, ressaltando que a velocidade desse processo depende da permeabilidade do tegumento, temperatura e composição química da semente. No entanto, as sementes de paricá apresentam tegumento muito resistente, o que pode ter impedido à entrada de água, resultando em uma baixa taxa de germinação, o que por sua vez, também pode ter influenciado na baixa taxa de sementes infectadas.

Oliveira et al. (2012) ratifica que a avaliação do teste de sanidade pode ser influenciada pela presença de microrganismos que colonizam superficialmente as sementes e, embora sejam considerados de importância secundária, dificultam ou impedem o desenvolvimento de fungos potencialmente causadores de problemas ao embrião e às plântulas. Ademais, as sementes utilizadas neste experimento não sofreram nenhum processo de escarificação. De acordo com Cruz et al. (2006), sementes de paricá não escarificadas possuem uma germinação mais lenta e desuniforme, iniciada nos dez primeiros dias após o semeio. Fernandes et al. (2019) em seu estudo sobre a análise do melhor método para a quebra de dormência, verificou que a técnica de escarificação mais eficiente foi a escarificação com lixa, técnica de baixo custo e 
fácil aplicabilidade, apresentando os mais altos valores de germinação e de mudas normais.

Referente à incidência fúngica das sementes de paricá (Schizolobium amazonicum Huber ex. Ducke) foram identificados os seguintes gêneros fúngicos: Penicillium sp. (40\%), Trichoderma sp. (21,1\%), Aspergillus niger (17,8\%) Aspergillus flavus (12,8\%) e Aspergillus glaucus (8,3\%) (Figura 1). As maiores incidências fúngicas correspondem aos gêneros Penicillium sp., e Tricoderma sp. Os fungos Aspergillus sp., Penicillium sp., Trichoderma sp. são saprófitas (CARMO et al., 2017). Em trabalhos semelhantes, Aspergillus flavus, A. niger, Penicillium griseofulvum, Penicillium sp. e Pestalotiopsis sp. também foram detectadas em sementes de paricá (Schizolobium amazonicum) (OLIVEIRA et al., 2012).

Leão et al. (2011) ao realizarem seu estudo sobre a avaliação fisiológica e sanitária de diferentes lotes de sementes de paricá também identificaram a presenças de fungos dos gêneros Aspergillus sp., e Penicillium $s p$. ., e verificaram que estes influenciaram diretamente na germinação e no bom desenvolvimento de plântulas causando infecção. Ademais, estes dois gêneros de fungos, Aspergillus sp., e Penicillium sp., estão associadas as condições de armazenamento das sementes, como a umidade, temperatura e as condições fisiológicas das sementes (teor de água) (CIRIO et al., 2003; JAYARAMAN et al., 2011; LEÃO et al., 2011). Estudo realizado por Cirio et al. (2003) verificaram que o gênero Aspergillus tem um grande potencial de redução na germinação das sementes e grãos, reduzindo de 92\% para 36\% entre 210 e 270 dias de armazenamento, respectivamente. $\mathrm{O}$ autor ainda destaca que esse gênero possui como característica desenvolver-se em baixa umidade, produzindo micotoxinas como aflatoxina nas sementes.

Referente às análises realizadas in vitro para avaliação do efeito dos isolados de Pseudômonas sp. e Burkholderia sp. para o controle de fitopatógenos pode-se perceber um crescente efeito desses isolados e suas combinações na redução de fitopatógenos de sementes em condições de laboratório. De acordo com a tabela 01, houve total redução de sementes infectadas quando tratadas com as rizobactérias em relação às tratadas pela testemunha, obtendo-se uma correlação positiva e significativa entre o parâmetro controle de fitopatógenos em sementes de paricá e uso de rizobactérias.

Tabela 1: Efeito dos isolados de Pseudômonas sp. e Burkholderia sp. no controle de fitopatógenos em sementes de paricá (Schizolombium amazonicum) experimento realizado em laboratório.

\begin{tabular}{|c|c|}
\hline Tratamentos & Média ${ }^{\circ}$ colônias* \\
\hline T1 - Sementes não microbiolizada ( $\mathrm{g} \mathrm{L}^{-1}$ ) & 15,8 a \\
\hline T2 - Sementes microbiolizadas com Pseudômonas sp ( $\left.\mathrm{g} \mathrm{L}^{-1}\right)$ & $0 \mathrm{~b}$ \\
\hline T3 - Sementes microbiolizadas com Burkholderia sp ( $\left.\mathrm{g} \mathrm{L}^{-1}\right)$ & $0 \mathrm{~b}$ \\
\hline T4 - Sementes microbiolizadas com Pseudômonas sp. e Burkholderia sp. ( $\left.\mathrm{g} \mathrm{L}^{-1}\right)$ & $0 \mathrm{~b}$ \\
\hline CV (\%) & 33,56 \\
\hline $\mathrm{P}$ & 0,00 \\
\hline
\end{tabular}

O parâmetro de germinação foi observado com o intuito de verificar a extensão da abrangência de germinação induzidas por rizobactérias. Segundo a tabela 02, os tratamentos analisados aos 10 e 30 dias não foram significativos a nível de $5 \%$ de probabilidade. Aos 20 dias após a germinação, o resultado foi significativo para a testemunha e para o tratamento T4.

A maior parte das pesquisas sobre agentes de controle biológico são de Pseudômonas spp., 
entretanto, ao longo das duas últimas décadas, o estudo com espécies de Burkholderia spp., vem expandindo. Isso porque, várias espécies de Burkholderia spp., possuem a habilidade de produzir compostos com atividade de biocontrole, fixadoras de nitrogênio, biorremediação e promoção do crescimento de plantas, características potencialmente utilizadas como agentes do controle biológico de fungos fitopatogênicos (COENYE et al., 2003). Um autor destaca que utilizar inoculantes microbianos combinados, tende a ter um efeito mais estimulador de crescimento maior do que inoculantes individuais, o que corrobora com nosso estudo, ao analisarmos as rizobactérias Pseudômonas sp. e Burkholderia sp. associadas.

Em relação aos parâmetros de comprimento da parte aérea, raiz das mudas, diâmetro de caule, massa fresca e seca da parte aérea e da raiz das mudas de Paricá não houve diferença significativa a entre os tratamentos e a testemunha. Logo, os efeitos das rizobactérias nas mudas de paricá não apresentaram resultado efetivo na fase inicial das mudas, dentro de 30 dias, período deste experimento. Desse modo, a ausência de resposta das rizobactérias pode ser devido a algumas plantas necessitarem de mais tempo para estabelecimento da simbiose efetiva, podendo este tempo ser superior ao tempo da inoculação, o que pode representar que o efeito benéfico das rizobactérias pode ser em estádios mais tardios (SILVA et al., 2006), fator este, a ser levado em consideração para os próximos estudos com sementes de paricá.

Tabela 2: Parâmetros de germinação e de crescimento das plantas em casa de vegetação.

\begin{tabular}{|c|c|c|c|c|c|c|c|c|c|c|}
\hline \multirow{2}{*}{$\begin{array}{l}\text { TRATAMENTO } \\
\left(\mathrm{g} \mathrm{L}^{-1}\right)\end{array}$} & \multicolumn{3}{|c|}{ GERMINAÇÃO } & \multirow{2}{*}{$\operatorname{AP}(\mathrm{cm})$} & \multirow{2}{*}{ CR $(\mathrm{cm})$} & \multirow{2}{*}{$\mathrm{DB}(\mathrm{mm})$} & \multicolumn{2}{|c|}{ BIOMASSA FRESCA } & \multicolumn{2}{|c|}{ BIOMASSA SECA } \\
\hline & 10 & 20 & 30 & & & & MPA & MR & MPA & MR \\
\hline T1 & 0,80 & $3,4 \mathrm{a}$ & 4,20 & 24,72 & 13,96 & 3,98 & 4,12 & 2,77 & 1,07 & 0,28 \\
\hline $\mathrm{T} 2$ & 0,40 & $1,2 \mathrm{~b}$ & 2,80 & 19,56 & 12,78 & 3,94 & 3,27 & 1,79 & 0,75 & 0,15 \\
\hline T3 & 0,60 & $0,8 \mathrm{~b}$ & 2,60 & 17,82 & 12,18 & 4,00 & 3,06 & 1,99 & 0,70 & 0,19 \\
\hline T4 & 0,40 & $4,06 \mathrm{a}$ & 3,00 & 17,26 & 13,96 & 4,06 & 3,72 & 2,17 & 0,86 & 0,17 \\
\hline CV & 114,79 & 66,63 & 36,84 & 23,50 & 32,28 & 10,59 & 33,47 & 45,89 & 36,48 & 41,04 \\
\hline$P$ & 0,7150 & 0,0014 & 0,1921 & 0,0838 & 0,8832 & 0,0894 & 0,5540 & 0,4634 & 0,1587 & 0,0871 \\
\hline
\end{tabular}

*Médias seguidas da mesma letra na coluna não diferem entre si, pelo teste de Tukey a nível de $5 \%$.

$\mathrm{CV}=$ coeficiente de variação; $\mathrm{AP}=$ Altura de planta; $\mathrm{CR}=$ Comprimento da Raiz; $\mathrm{DB}=$ Diâmetro basal; $\mathrm{MPA}=\mathrm{Massa}$ da parte aérea; $M R=$ Massa raiz.

Em estudo semelhante, Lima (2018) estudou sobre o efeito da inoculação de microrganismos indutores de crescimento e adubação química em paricá em solo arenoso em São Domingos do Araguaia PA, no qual a inoculação com rizobactérias promotoras de crescimento em plantas- RPCP (Enterobacter sp., Enterobacter aerogenes, Bacillus sp. e Pantoea $s p$ ) e os fungos micorrizícos arbusculares - FMAs (Glomus ethunicatum e Glomus Clarum) não influenciaram no desenvolvimento em diâmetro, altura e sobrevivência das plantas de paricá.

\section{CONCLUSÕES}

As sementes de paricá (Schizolobium amazonicum) apresentaram baixa taxa de germinação e infestação fúngica, a maioria estavam sadias. Identificou-se as espécies fúngicas: Aspergillus flavus, Penicillium sp., Aspergillus glaucus, Aspergillus niger e Trichoderma sp., infectando as sementes. Ocorreu total redução da incidência fúngica nas sementes tratadas com as rizobactérias Pseudômonas sp. e Burkholderia sp.. Os parâmetros de germinação, altura de planta, comprimento da raiz, diâmetro basal, biomassa fresca e seca da parte aérea e raiz não foram influenciados com a microbiolização das sementes, 
realizadas antes do plantio.

No decorrer do presente estudo, observou-se a existências de vários estudos com culturas florestais que avaliaram os efeitos das rizobactérias no crescimento de mudas como o Pinus (BRUNETTA et al., 2010), em Eucalyptus spp. (MAFIA et al., 2007; TEIXEIRA et al., 2007; MAFIA et al., 2009), no entanto, poucos são os estudos que avaliam o potencial das rizobactérias em espécies florestais nativas (CUNHA et al., 2013), como o paricá. Assim, é necessário investir em mais projetos de tecnologia de baixo custo voltados para as espécies florestais nativas lenhosas, principalmente as espécies de grande interesse econômico e alternativas para minimização da pressão do desmatamento no bioma amazônico, como o paricá. Ademais, essas tecnologias podem promover o rápido crescimento das plantas, diminuir a ocorrência de fitopatôgenos/ doenças e elevar a produtividade, sendo uma excelente alternativa de sucesso frente as preocupações ambientais e econômicas.

\section{REFERÊNCIAS}

AMATA. Revisão sobre paricá: Schizolobium amazonicum Huber ex. Ducke. São Paulo: AMATA, 2009.

BRASIL. Ministério da Agricultura, Pecuária e Abastecimento. Secretaria de Defesa Agropecuária. Manual de Análise Sanitária de Sementes. Brasília: Mapa, 2009.

BRUNETTA, J. M. F. C.; ALFENAS, A. C.; MAFIA, R. G.; GOMES J. M.; BINOTI, D. B.; FONSECA, N. A. N.. Isolamento e seleção de rizobactérias promotoras do crescimento de Pinus taeda. Revista Árvore, Viçosa, v.34, n.3, p.399-406, 2010. DOI: https://doi.org/10.1590/S0100-67622010000300003

CARMO, A. L. M.; MAZARATTO, E. J.; ECKSTEIN, B.; SANTOS, A. F.. Associação de fungos com sementes de espécies florestais nativas. Summa Phytopathologica, Botucatu, v.43, n.3, p.246-247, 2017.

CARVALHO, P. E. R.. Paricá: Schizolobium amazonicum. Colombo: Embrapa Florestas, 2007.

CELY, M. V. T.; SIVIERO, M. A.; EMILIANO, J.; SPAGO, F. R.; FREITAS, V. F.; BARAZETTI, A. R.; GOYA, E. T.; LAMBERTI, G. D. S.; SANTOS, I. M. O.; OLIVEIRA, A. G.; ANDRADE, G.. Inoculation of Schizolobium parahyba with Mycorrhizal Fungi and Plant Growth-Promoting Rhizobacteria Increases Wood Yield under Field Conditions. Frontiers in Plant Science, v.7, p.1-13., 2016. DOI: https://doi.org/10.3389/fpls.2016.01708

CESA-LUNA, C.; BAEZ, A.; QUINTERO-HERNÁNDEZ, V.; LA CRUZ-ENRÍQUEZ, J.; CASTAÑEDA-ANTONIO, A. M.; MUÑOZROJAS, J.. The importance of antimicrobial compounds produced by beneficial bacteria on the biocontrol of phytopathogens. Acta Biológica Colombiana, v.25, n.1, p.140-154, 2020.

DOI: https://doi.org/10.15446/abc.v25n1.76867

CIRIO, G. M.; LIMA, M. L. R. Z. C.. Métodos de detecção do gênero Aspergillus em sementes de milho (Zea mays I.) em 270 dias de armazenamento. Visão Acadêmica, Curitiba, v.4, n.1, p.19-23, 2003. DOI:

https://doi.org/10.5380/acd.v4i1.518
COENYE, T.; VANDAME, P.. Diversity and significance of Burkholderia species occupying diverse ecological niches. Environmental Microbiology, v.5, n.9, p.719-729, 2003. DOI: https://doi.org/10.1046/j.1462-2920.2003.00471.x

CRUZ, E. D.; CARVALHO, J. E. U.. Methods of overcoming dormancy in Schizolobium amazonicum Huber ex Ducke (Leguminosae - Caesalpinioideae) seeds. Revista Brasileira de Sementes, v.28, n.3, p.108-115, 2006. DOI: https://doi.org/10.1590/S0101-31222006000300016

CUNHA, J. F.; ALFENAS, A. C.; SILVA, A. G.; BRANDÃO, I. J.. Potencial de rizobactérias no crescimento de mudas de Sibipiruna (Caesalpinia peltophoroides BENTH). Revista Árvore, Viçosa, v.37, n.2, p.211-218, 2013. DOI: https://doi.org/10.1590/S0100-67622013000200002

FERNANDES, R. D. O.; PINHO NETO, O. L. Ç.; SANTOS, J. S. ALMEIDA, A. D. D. S.; PINCANÇO, L. I. B.; MACIEL, C. G. Dormancy overcoming of Schizolobium amazonicum Huber ex Ducke. (Caesalpinoideae) seeds. Ciência Agrícola, Rio Largo, v.17, n.3, p.41-44, 2019.

FERREIRA, D. F.. Análises estatísticas por meio do Sisvar para windows versão 4.0. In: REUNIÃO ANUAL DA RBRAS. Anais. 2000. p.255-258.

FREITAS, S. S.. Rizobactérias promotoras do crescimento de plantas. In: SILVEIRA, A. P. D.; FREITAS, S. S.. Microbiologia do solo e qualidade ambiental. Instituto Agronômico, Campinas, 2007. p.1-20.

GOMES, J. M.; SILVA, J. C. F.; VIEIRA, S. B.; CARVALHO, J. O. P. D.; OLIVEIRA, L. C. L. Q.; QUEROZ, W. T. D.. Schizolobium parahyba var. amazonicum (Huber ex Ducke) Barneby pode ser utilizada em enriquecimento de clareiras de exploração florestal na Amazônia. Ciência Florestal, Santa Maria, v.29, n.1, p.417-424, 2019. DOI:

https://doi.org/10.5902/198050984793

IWAKIRI, S.; MATOS, J. L. M.; PINTO, J. A.; VIANA, L. C.; SOUZA, M. M.; TRIANOSKI, R.; ALMEIDA, V. C.. Produção de painéis laminados unidirecionais - LVL com lâminas de Schizolobium amazonicum, Eucalyptus saligna e Pinus taeda. 
Cerne, Lavras, v.16, n.4, p.557-563, 2010.

DOI: https://doi.org/10.1590/S0104-77602010000400015

JAYARAMAN, P.; NESAPRIYA, S.; PARAMESHWARI, S.; SHYAMALA PRIYA, S.; JAWAHAR, N.; SEKAR-BABU, H. Occurrence of storage fungi in jatropha (Jatropha curcas L.) seeds. African Journal of Microbiology Research, v.5, n.5, p.475-480, 2011. DOI: https://doi.org/10.5897/AJMR10.865

LEÃO, N. V. M.; BARBOSA, L. V. A.; BENCHIMOL, R. L.; SILVA, C. M.; FELIPE, S. H. S.; SHIMIZU, E. S. C.. Avaliação fisiológica e sanitária de diferentes lotes de sementes de paricá (Schizolobium parahyba var. amazonicum (Huber ex Ducke) Barneby) utilizada em SAFs. In: CONGRESSO BRASILEIRO DE SISTEMAS AGROFLORESTAIS, 8. Anais. Belém: SBSAF, 2011.

LIMA, A. O. D. S.. Respostas de paricá e clones de eucalipto à inoculação de fungos micorrízicos e rizobactérias em área de neossolo quartzarênico em São Domingos do AraguaiaPA. Dissertação (Mestrado em Ciências Florestais) Universidade Federal Rural da Amazônia, Belém, 2018.

MAFIA, R. G; ALFENAS, A. C.; MAFFIA, L. A.; FERREIRA, E. M.; SIQUEIRA, L.. Efeito de rizobactérias sobre o enraizamento e crescimento de clones de eucalipto em diferentes condições de propagação clonal. Revista Árvore, v.31, n.5, p.813-821, 2007. DOI: https://doi.org/10.1590/S010067622007000500005

MAFIA, R. G.; ALFENAS, A. C.; MAFFIA, L. A.; FERREIRA, E. M.; BINOTI, D. H. B.; SIQUEIRA, L.. Microbiolização e interação entre rizobactérias promotoras do crescimento e clones de eucalipto. Revista Árvore, v.35, n.5, p.789-797, 2009. DOI: https://doi.org/10.1590/S0100-67622009000500002

MARQUES, L. C. T.; YARED, J. A. G.; SIVIERO, M. A.. A evolução do conhecimento sobre o Paricá para reflorestamento no Estado do Pará. Circular Técnica 158. Belém: Embrapa, 2006.

MOIN, S.; ALI, S. A.; HASAN, K. A.; TARIQ, A.; SULTANA, V.; ARA, J.; EHTESHAMUL-HAQUE, S.. Managing the root rot disease of sunflower with endophytic fluorescent Pseudomonas associated with healthy plants. Cop Protection, v.130, p.1-10, 2020. DOI: https://doi.org/10.1016/j.cropro.2019.105066

NASCENTE, A. S.; FILIPP, M. C. C.; LANNA, A. C.; SOUZA, A. C. A.; LOBO, V. L. D. S.; SILVA, G. B.. Biomass, gas exchange, and nutrient contents in upland rice plants affected by application forms of microorganism growth promoters. Environmental Science and Pollution Research, v.24, p.2956-2965. DOI: https://doi.org/10.1007/s11356-0168013-2

NUNES, Y. R. F.; FAGUNDES, M.; ALMEIDA, H. S.; VELOSO, M. D. M.. Aspectos ecológicos da aroeira (Myracrodruon urundeuva Allemão - Anacardiaceae): fenologia e germinação de sementes. Revista Árvore, Viçosa, v.32, n.2, p.233-243, 2008. DOI: https://doi.org/10.1590/S0100$\underline{67622008000200006}$

OLIVEIRA, J. D.; SILVA, J. B.; DAPONT, E. C.; SOUZA, L. M. S.; RIBEIRO, S. A. L.. Métodos para detecção de fungos e assepsia de sementes de Schizolobium amazonicum (Caesalpinioideae). Bioscience Journal, Uberlandia, v.28, n.6, p.945-953, 2012.
PHOUR, M.; SUNDHU, S. S.. Amelioration of salinity stress and growth stimulation of mustard (Brassica juncea L.) by salt-tolerant Pseudomonas species. Applied Soil Ecology, v.149, p.1-10, 2020. DOI:

https://doi.org/10.1016/j.apsoil.2020.103518

RODRÍGUEZ, A.; CASTREJÓN-GODINEZ, M. L.; SALAZARBUSTAMANTE, E.; GAMA-MARTÍNEZ, Y.; SÁNCHEZ-SALINAS, E.; MUSSALI-GALANTE, P.; TOVAR-SÁNCHEZ, E.; ORTIZHERNÁNDEZ, M.. Omics Approaches to Pesticide Biodegradation, Current Microbiology, v.77, p.545-563, 2020. DOI: https://doi.org/10.1007/s00284-020-01916-5

ROMEIRO, R. S.. Bactérias Fitopatogênicas. 2 ed. Viçosa: UFV, 2005

ROMEIRO, R. S.. Controle biológico de doenças de plantas: Fundamentos. Viçosa - MG: UFV, 2007.

RUFINO, C. P. B.; ARAÚJO, C. S.; NOGUEIRA, S. R.. Desafios na utilização do controle de biológicos de doenças de plantas na Amazônia. South American Journal of Basic Education, Technical and Technological, v.5, n.1, p.248-262, 2018.

SHILEV, S.; BABRIKOVA, I.; BABRIKOV, T.. Consortium of plant growth-promoting bacteria improves spinach (Spinacea oleracea L.) growth under heavy metal stress conditions. Journal of Chemical Technology \& Biotechnology, v.95, n.4, p.932-939, 2019. DOI: https://doi.org/10.1002/ictb.6077

SILVA, A. R.; SALES, A.. Crescimento e produção de paricá em diferentes idades e sistemas de cultivo. Avances in Foresty Science, Cuiabá, v.55, n.1, p.231-235, 2018.

SILVA, M. D.; SILVA, F. D.; YANO-MELO, A. M.; MELO, N. D.; MAIA, L. C.. Fungos micorrízicos arbusculares e vermicomposto na aclimatação de Alpinia purpurata (Viell.) Schum e Zingiber spectabile Griff. (Zingiberaceae). Acta Botânica Brasílica, v.20, n.2, p.249-256, 2006. DOI: https://doi.org/10.1590/S0102-33062006000200001

SIVIERO, M. A.; MOTTA, A. M.; LIMA, D. D. S.; BIROLLI, R. R.; HUH, S. Y.; SANTINONI, I. A.; MURATE, L. S.; CASTRO, C. M. A.; MIYAUCHI, M. Y. H.; ZANGARO, W.; NOGUEIRA, M. A.; ANDRADE, G.. Interaction among $\mathrm{N}$-fixing bacteria and $\mathrm{AM}$ fungi in Amazonian legume tree (Schizolobium amazonicum) in field conditions. Applied Soil Ecology, v.39, n.2, p.144152, 2008. DOI:

https://doi.org/10.1016/i.apsoil.2007.12.004

SOUZA, C. R. D.; ROSSI, L. M. B.; AZEVEDO, C. P. D.; VIEIRA, A. H.. Paricá: Schizolobium parahyba var. amazonicum (Huber $x$ Ducke) Barneby. Circular Técnica 18. Manaus: Embrapa Amazônia Ocidental, 2003.

TEIXEIRA, D. A.; ALFENAS, A. C.; MAFIA, R. G.; MACHADO, E. M.; SIQUEIRA, L.; MAFFIA, L. A.; MOUNTEER, A. H. Rhizobacterial promotion of eucalypt rooting and growth Brazilian Journal of Microbiology, v.38, n.1, p.118-123, 2007. DOI: https://doi.org/10.1590/S1517$\underline{83822007000100025}$

VIEIRA JÚNIOR, J. R.; FERNANDES, C. D. F.; ANTUNES JÚNIOR, H.; SILVA, M. S.; SILVA, D. S. G.; SILVA, U. O.. Rizobactérias como agentes de controle biológico e promotores de crescimento de plantas. Porto Velho: Embrapa Rondônia, 
2013.

WANG, M.; BIAN, Z.; SHI, J.; WU, Y.; XU,Y.; YANG, Y.; NI, H.; CHEN, H.; BIAN, X.; LI, T.; ZHANG, Y.; JIANG, L.; TU, Q.. Effect of the nitrogen-fixing bacterium Pseudomonas protegens CHAO-AretSnif on garlic growth under different field conditions. Industrial Crops \& Products, v.145, p.1-8, 2020. DOI: https://doi.org/10.1016/j.indcrop.2019.111982

A CBPC - Companhia Brasileira de Produção Científica (CNPJ: 11.221.422/0001-03) detém os direitos materiais desta publicação. Os direitos referem-se à publicação do trabalho em qualquer parte do mundo, incluindo os direitos às renovações, expansões e disseminações da contribuição, bem como outros direitos subsidiários. Todos os trabalhos publicados eletronicamente poderão posteriormente ser publicados em coletâneas impressas sob coordenação da Sustenere Publishing, da Companhia Brasileira de Produção Científica e seus parceiros autorizados. Os (as) autores (as) preservam os direitos autorais, mas não têm permissão para a publicação da contribuição em outro meio, impresso ou digital, em português ou em tradução. 